

\title{
Multiple Antenna Channel Characterisation for Wearable Devices in an Indoor Stairwell Environment
}

Catherwood, P., \& Scanlon, W. (2017). Multiple Antenna Channel Characterisation for Wearable Devices in an Indoor Stairwell Environment. IET Microwaves, Antennas and Propagation. https://doi.org/10.1049/ietmap.2017.0274

\section{Published in:}

IET Microwaves, Antennas and Propagation

\section{Document Version:}

Peer reviewed version

\section{Queen's University Belfast - Research Portal:}

Link to publication record in Queen's University Belfast Research Portal

\section{Publisher rights}

(C) 2017 Institution of Engineering and Technology.

This work is made available online in accordance with the publisher's policies. Please refer to any applicable terms of use of the publisher.

\section{General rights}

Copyright for the publications made accessible via the Queen's University Belfast Research Portal is retained by the author(s) and / or other copyright owners and it is a condition of accessing these publications that users recognise and abide by the legal requirements associated with these rights.

Take down policy

The Research Portal is Queen's institutional repository that provides access to Queen's research output. Every effort has been made to ensure that content in the Research Portal does not infringe any person's rights, or applicable UK laws. If you discover content in the Research Portal that you believe breaches copyright or violates any law, please contact openaccess@qub.ac.uk. 


\title{
Multiple Antenna Channel Characterisation for Wearable Devices in an Indoor Stairwell Environment
}

\author{
Philip A. Catherwood ${ }^{1 *}$, William G. Scanlon ${ }^{2}$ \\ ${ }^{1}$ School of Engineering, Ulster University, Shore Road, Jordanstown, UK \\ ${ }^{2}$ School of Electronics, Electrical Engineering and Computer Science, Queen's University, Belfast, UK \\ p.catherwood@ulster.ac.uk
}

\begin{abstract}
Any building with more than one floor will have stairwells of some form, yet this area is often neglected in channel characterization studies. We present fading channel models and examine attainable spatial diversity gains at $90 \%$ signal reliability for an off-body multiple antenna system at frequencies of 3,4 , and $5 \mathrm{GHz}$ in an indoor stairwell. Additionally we investigate received power, mutual coupling and channel cross-correlation, signal combining modelling, and antenna spatial diversity; the authors believe this is a valuable advancement beyond current knowledge to understand wearable MIMO technology in stairwell environments. Results reveal that 2-branch spatial diversity techniques offer signal gains over individual single channels in the range of 1.7 to $3.3 \mathrm{~dB}$ for LOS and 1.8 to $3.4 \mathrm{~dB}$ for NLOS for each of the three investigated frequencies, while 3-channel diversity combining appears to offer no significant additional gain over the 2branch combinations. Furthermore, for NLOS cases the best fit statistical distribution channel models were found to change when spatial diversity was utilized; this highlights mitigated channel fading and increased signal reliability.
\end{abstract}

\section{Introduction}

Multiple-antenna technology is a popular wireless technique yielding increased bandwidth, throughput and signal gain [1]. However, for wearable applications the proximity to the user's body will affect antenna-to-antenna interactions [2], whilst body geometry limits both the number and spacing of elements [3]. Antenna arrays are often employed to realize a diversity gain over a singlechannel equivalent, with the nature of the multipath environment and the channel fading characteristics dictating overall performance [4].

Multiple-antenna technology is traditionally used for narrowband systems to alleviate the effects of multipath fading [5]. While the deleterious effects of fading cannot be fully eliminated, fading channel characterization and modelling can be used to establish the performance of multiple-antenna systems. As well as providing valuable insight and understanding, fading channel characterization enables system designers to establish if the extra cost and complexity of such systems is beneficial and worthwhile. Off-body results in the area typically highlight that diversity gains in the region of $5.7 \mathrm{~dB}$ can be obtained using a dualbranch bodyworn maximal-ratio diversity system in a large open office [6], achievable through utilization of the inherent increased physical aperture of multiple antenna systems [7].

Wearable devices have many practical applications and there are a number of scenarios where operation in a stairwell environment is essential. Such examples would include armed forces undertaking combat activities, office workers going between floors during their daily activities, and rescue workers in a multi-story office building [8]. Most buildings in urban areas are constructed over more than one level and as such stairwells are prolific in modern metropolitan environments, thus it is evident that understanding the propagation channel for wearable wireless systems operating within stairwells is essential. Numerous empirical measurements have been taken in open offices, corridors, open-plan buildings, conference halls, etc., but no work exists to investigate off-body multiple-antenna systems in a stairwell environment. This is an overlooked but important area of study as most buildings have more than one floor and it is unrealistic to assume users will use their devices in all areas of a building except the stairwells.

Channel characterization results for stairwells have been presented for narrowband, fixed antenna locations and non-wearable applications, with [9] at $2.4 \mathrm{GHz}$ and $5.8 \mathrm{GHz}$ for the transmitter and receiver indoor, [10] at $2.4 \mathrm{GHz}$ with the transmitter outside the building, and [11] at $2.6 \mathrm{GHz}$ for MIMO arrangements. Other work has studied multiple antennas for the off-body links which reported upon diversity reception techniques for use in multiple-antenna wearable systems operating at $868 \mathrm{MHz}$ with up to 6 branches [6], improvement in reliability in wireless links at $2.45 \mathrm{GHz}$ [8], and the optimization of antenna positioning for maximum diversity performance at 3.1 to $10.6 \mathrm{GHz}$ [12]. It is suggested by [12] that their presented results are not only applicable to UWB, but that similar benefits can be realized for narrowband communications. The significance of stairwell structures in radio science was recognized in [9] where understanding propagation in stairwells was highlighted as important for emergency applications and effective indoor communications systems.

Other significant non-bodyworn work conducted in stairwells includes [13-15]. Research by [13] presented analysis of three most commonly utilized indoor empirical path loss models for a dog-leg staircase using measurements at $900 \mathrm{MHz}$ and $1800 \mathrm{MHz}$. While the work did not investigate bodyworn antennas and used single antennas it highlighted path loss values at these frequencies. The effects of varying antenna heights on path loss at frequencies between 2.50-2.69 GHz were reported by [14, 15], with [14] establishing how antenna height directly effects path losses in stairwells. This was developed further by [15] to include 
differing stairwell structures and layouts, and additional measurement positions within the environment.

The presented work differs from each of the above publications in that it is focused on wearable multiple array antenna systems for mobile users with measurements made in the time domain to capture the fading effects due to the inherent biomechanical movement of the dynamic user as they walked within the environment. These issues are important to future development of wearable computing and as yet have not been explicitly addressed in literature.

This work investigates empirical off-body channels for a wearable multi-antenna transmitter and a wall-mounted base station in an indoor stairwell environment, and investigates mutual coupling effects on received power and diversity gain when selective diversity channel combination techniques are employed. Additionally, statistical models are developed for the various empirical results and the effects of channel combining investigated.

\section{Environment and measurement equipment}

\subsection{Environment}

A generic stairwell (Fig. 1a) was chosen which had typical characteristics; a full size U-shaped staircase over five floors with inter-floor mezzanines, vinyl flooring, handrails and stair edging. The 5.5(L) x $2.5(\mathrm{~W}) \times 3.6(\mathrm{H}) \mathrm{m}$ stairwell was of $1960 \mathrm{~s}$ concrete construction and situated between floors two and three of the Ulster University, UK. The height of each step was $17 \mathrm{~cm}$ with a tread of $27 \mathrm{~cm}$ and each flight had 11 steps.

The investigative focus of the work was to research how the use of spatial diversity for a wearable system can impact on the robustness of the off-body radio system in a stairwell. A single stairwell was selected (based on its generic layout, geometry, construction, etc.) as a means to this investigation. Confidence to use a single stairwell measurement is supported by [16-18] who addressed their research hypothesis in a single stairwell, and also by the study of [19] who conducted their work using four distinct



Fig. 1. Measurement environment and equipment

(a) Stairwell, (b) Bodyworn optical measurement multiple antenna transmitter stairwells where it was generally observed that path loss in the environment was not strikingly different and that the geometrically regular and enclosed nature of the typical stairwell has the capacity to offer a generalised result.

\subsection{Measurement Equipment}

This work uses optical fibre antenna feeds to mitigate the effects of the use of co-axial cables for channel sounding [20] and has been conducted for real-time dynamic natural user movements. The ultra-wideband body-worn multiple antenna channel characterization system (Fig. 1b) was previously reported in [21]. The system sequentially measures the complex single-in single-out impulse responses between the combinations of the transmitters and receiver. The wearable transmitting antenna array was positioned on the user's chest ( $1.4 \mathrm{~m}$ above floor level) and held against the body using an elastic cuff to minimize body-antenna separation [22]. The transmit time on each channel was $10 \mathrm{~ms}$, with a full cycle through all channels taking $30 \mathrm{~ms}$ and a channel switching speed of $50 \mathrm{~ns}$.

A receive base station was mounted on the wall at a height of $2.2 \mathrm{~m}$ above the floor as depicted in Fig. 1a to emulate an indoor wireless access point. The propagation channel was sampled at a rate of 33 scans per second for each of the 3 antenna to base-station branches (the Doppler frequency for such a mobile transmitter is less than $10 \mathrm{~Hz}$ ). A frequency-domain technique requiring the recording of a reference measurement in an RF anechoic chamber was employed to de-convolve the measurement system from the received signal, leaving only the transfer function of the propagation channel. The recorded measurements were postprocessed using Matlab to extract power delay profiles (PDP) for each antenna. The PDPs were further processed to yield received power for each channel at three specific frequencies of interest; 3, 4 and $5 \mathrm{GHz}$. The test user was an adult male of mass $82 \mathrm{~kg}$, height $1.78 \mathrm{~m}$.

Tests were subdivided into two categories for each environment: line of sight (LOS) or non-LOS (NLOS), depending on the orientation of the worn antennas with respect to the receive antenna. LOS tests were conducted with the user (and transmitting array) directly facing the Rx antenna and NLOS completed $180^{\circ}$ from the LOS position (directly facing away). Tests were conducted along a $5 \mathrm{~m}$ path rising from the mezzanine area between the second and third floor and walking naturally up the stairs at $0.5 \mathrm{~ms}-1$ to the entrance platform area for level 3 where the wireless access point was positioned. The return journey (NLOS) using the same walking speed and path.

\subsection{Antenna Separation Distance}

Spatial diversity gain and the correlation between channels of a multiple-antenna system is a function of the antenna separation distance, with correlation generally decreasing as the separation distance increases [23]. The dimensions of the rectangular geometrical antenna array were carefully selected (Fig. 1b.) for frequencies between 3$5 \mathrm{GHz}$ to meet the recommended cross-correlation coefficient (CCC) criterion (0.7 or less); this was to ensure the signals on each channel are suitably de-correlated to facilitate maximum theoretical diversity gain [24]. 
This article has been accepted for publication in a future issue of this journal, but has not been fully edited. Table 1 Statistical parameter estimates for received power

\begin{tabular}{|c|c|c|c|c|c|c|c|}
\hline & & \multirow[b]{3}{*}{ Channel } & \multirow[b]{3}{*}{ Distribution } & \multicolumn{4}{|c|}{ Statistical parameters } \\
\hline & & & & \multicolumn{2}{|c|}{$\mu$} & \multicolumn{2}{|c|}{$\sigma$} \\
\hline & & & & Est. & Std. Err. & Est. & Std. Err. \\
\hline \multirow{6}{*}{$3 \mathrm{GHz}$} & \multirow{3}{*}{ LOS } & 1 & Weibull & $a=50.3$ & $a=0.465$ & $\mathrm{~b}=12.4$ & $b=1.05$ \\
\hline & & 2 & Weibull & $a=49.3$ & $a=0.438$ & $\mathrm{~b}=13.2$ & $\mathrm{~b}=1.11$ \\
\hline & & 3 & Weibull & $a=49.4$ & $a=0.410$ & $\mathrm{~b}=14.1$ & $\mathrm{~b}=1.16$ \\
\hline & \multirow{3}{*}{ NLOS } & 1 & Normal & -56.5 & 0.438 & 4.38 & 0.312 \\
\hline & & 2 & Normal & -56.4 & 0.471 & 4.71 & 0.336 \\
\hline & & 3 & Normal & -57.2 & 0.405 & 4.05 & 0.289 \\
\hline \multirow{6}{*}{$4 \mathrm{GHz}$} & \multirow{3}{*}{ LOS } & 1 & Rician & -45.5 & 0.384 & 3.63 & 0.272 \\
\hline & & 2 & Rician & -45.5 & 0.442 & 4.17 & 0.312 \\
\hline & & 3 & Rician & -46.0 & 0.491 & 4.64 & 0.347 \\
\hline & \multirow{3}{*}{ NLOS } & 1 & Normal & -49.6 & 0.564 & 5.64 & 0.402 \\
\hline & & 2 & Normal & -50.1 & 0.471 & 4.71 & 0.336 \\
\hline & & 3 & Normal & -50.4 & 0.424 & 4.24 & 0.302 \\
\hline \multirow{6}{*}{$5 \mathrm{GHz}$} & \multirow{3}{*}{ LOS } & 1 & Rician & -48.1 & $\mathrm{~s}=0.509$ & 4.80 & 0.360 \\
\hline & & 2 & Rician & -48.6 & $\mathrm{~s}=0.531$ & 5.01 & 0.376 \\
\hline & & 3 & Rician & -48.1 & $\mathrm{~s}=0.378$ & 3.58 & 0.267 \\
\hline & \multirow{3}{*}{ NLOS } & 1 & Normal & -51.9 & 0.524 & 5.24 & 0.373 \\
\hline & & 2 & Normal & -52.6 & 0.397 & 3.97 & 0.283 \\
\hline & & 3 & Normal & -52.6 & 0.418 & 4.18 & 0.298 \\
\hline
\end{tabular}

\section{Results}

\subsection{Received Power}

For the recorded received power levels statistical parameters for the cumulative distribution of the signals were estimated using Matlab, and the Akaike information criterion (AIC) used to select the closest fitting distribution. Table I reveals that for the LOS trial each of the three single channels for the measurements at $3 \mathrm{GHz}$ are best described by the Weibull distribution which has been a popular model for describing multipath fading channels for the indoor radio propagation channel [25]. Description of the channel as a Weibull fading channel; The Weibull distribution has a distribution with a peak at a higher power than for Rician. This may be attributed to the lower absorption of the signal within the environment at this lower frequency (with respect to $4 \mathrm{GHz}$ and $5 \mathrm{GHz}$ ) [26] and may also be affected by the dynamic movement of the limbs of the user. For the recorded received power levels statistical parameters for the cumulative distribution of the signals were estimated using Matlab, and the Akaike information criterion (AIC) used to select the closest fitting distribution. Table I reveals that for the LOS trial each of the three single channels for the measurements at $3 \mathrm{GHz}$ are best described by the Weibull distribution (each with differing statistical parameters), but measurements at $4 \mathrm{GHz}$ and $5 \mathrm{GHz}$ are best described by the Rician distribution (again with differing parameter estimates). The Rician distribution is employed to model propagation paths that consist of a dominant direct LOS component and many weaker components [27]. In the stairwell environment for a LOS arrangement there will be a direct path and various weaker components from the reflected/scattered signal.

For the NLOS case, each of the 3 individual antenna branches at 3,4 and $5 \mathrm{GHz}$ were best described by the Normal distribution. Normal (or Gaussian) distribution is typically best used to model a scenario with a dominant LOS component and minimal other components (often described as the result of the Rician $\mathrm{K}$ factor tending to infinity [27]). However, it has been presented as the best fit model at all three frequencies for the NLOS scenario (user walking directly away from the base station). It is recognised that the physical geometry of the stairwell environment offers many opportunities for the dominant



Fig. 2. Dynamic cross correlation coefficients for each channel combination in the stairwell environment. 
This article has been accepted for publication in a future issue of this journal, but has not been fully edited.

Content may change prior to final publication in an issue of the journal. To cite the paper please use the doi provided on the Digital Library page.

path to reflect off the various stairs, rails, orthogonal walls, etc. and as such it may be that for such an environment the dominant path is reflecting off the far wall in the stairwell to reach the base station with the consequence that the other non-direct components have less power if and when they reach the base station. Given the geometry of the stairwell these results suggest that there is significant power in this dominant path.

\subsection{Mutual Coupling and Cross-correlation}

Diversity schemes play an important role in addressing fading and shadowing effects in indoor radio environments. The popular spatial diversity scheme used here to combine channels investigates how this may increase signal reliability and profitably alter channel characteristics.

Observing Fig. 2, it is noted that all of the envelope cross correlation coefficients (CCC) were less than 0.7 for all the selected frequencies and bandwidths; the target threshold recommended in [24]. There appears a trend between relative antenna location and the channel correlation values. Antennas 1 and 2 are diagonally positioned, thus keeping the CCC to a lower level for the most part. Overall, it is noted that CCC is consistently low at $5 \mathrm{GHz}$ compared to the other results.

\subsection{Signal Combining Modelling}

Statistical parameters for signal combining were again investigated and the AIC used to select the closest fitting distribution (Table II). These results show that LOS measurements at $3 \mathrm{GHz}, 4 \mathrm{GHz}$ and $5 \mathrm{GHz}$ for both 2channel and also 3 -channel combining are best described by the same distribution as each of the individual channels were (albeit with differing statistical parameters each time). For NLOS measurements $3 \mathrm{GHz}$ and $5 \mathrm{GHz}$ distributions are found to change the best fit model, from Normal to Lognormal for both 2-channel and 3-channel combining, while $4 \mathrm{GHz}$ changes from Normal to Weibull for all channel-combining combinations. Such changes indicate that the diversity combining technique is successfully combatting fading as the selection of the antenna with the strongest signal increases link reliability for channel with a low (less than 0.7) cross-correlation coefficient; the change in distribution of the power of the received signal dataset highlights this occurrence.

\subsection{Antenna Spatial Diversity}

Diversity gains for received power at $90 \%$ signal reliability for two and three branch channel combining were investigated. Moderate diversity gains were found for the

Table 2 Statistical parameters for various channel combining

\begin{tabular}{|c|c|c|c|c|c|c|c|}
\hline & & \multirow[b]{4}{*}{$\begin{array}{c}\text { Channel } \\
\text { combination }\end{array}$} & \multirow[b]{4}{*}{ Distribution } & & & & \\
\hline & & & & \multicolumn{4}{|c|}{ Statistical parameters } \\
\hline & & & & \multicolumn{2}{|c|}{$\mu$} & \multicolumn{2}{|c|}{$\boldsymbol{\sigma}$} \\
\hline & & & & Est. & Std. Err. & Est. & Std. Err. \\
\hline \multirow{8}{*}{$3 \mathbf{G H z}$} & \multirow{4}{*}{ LOS } & 12 & Weibull & $a=51.7$ & $\mathrm{a}=0.353$ & $\mathrm{~b}=16.2$ & $\mathrm{~b}=1.36$ \\
\hline & & 13 & Weibull & $a=51.5$ & $\mathrm{a}=0.334$ & $\mathrm{~b}=17.2$ & $\mathrm{~b}=1.40$ \\
\hline & & 23 & Weibull & $\mathrm{a}=51.7$ & $a=0.370$ & $\mathrm{~b}=15.5$ & $\mathrm{~b}=1.29$ \\
\hline & & 123 & Weibull & $\mathrm{a}=51.5$ & $a=0.312$ & $\mathrm{~b}=18.3$ & $\mathrm{~b}=1.52$ \\
\hline & \multirow{4}{*}{ NLOS } & 12 & Lognormal & 3.91 & 0.00759 & 0.0761 & 0.00538 \\
\hline & & 13 & Lognormal & 3.91 & 0.00718 & 0.0722 & 0.00512 \\
\hline & & 23 & Lognormal & 3.91 & 0.00793 & 0.0779 & 0.00554 \\
\hline & & 123 & Lognormal & 3.91 & 0.00741 & 0.0744 & 0.00527 \\
\hline \multirow{8}{*}{$4 \mathrm{GHz}$} & \multirow{4}{*}{ LOS } & 12 & Rician & -44.4 & 0.355 & 3.36 & 0.251 \\
\hline & & 13 & Rician & -43.8 & 0.377 & 3.57 & 0.267 \\
\hline & & 23 & Rician & -43.8 & 0.447 & 4.22 & 0.316 \\
\hline & & 123 & Rician & -43.2 & 0.376 & 3.56 & 0.266 \\
\hline & \multirow{4}{*}{ NLOS } & 12 & Weibull & $a=55.0$ & $a=0.399$ & $b=13.7$ & $\mathrm{~b}=1.10$ \\
\hline & & 13 & Weibull & $\mathrm{a}=52.0$ & $a=0.400$ & $b=13.7$ & $\mathrm{~b}=1.10$ \\
\hline & & 23 & Weibull & $\mathrm{a}=51.8$ & $a=0.342$ & $b=15.9$ & $\mathrm{~b}=1.29$ \\
\hline & & 123 & Weibull & $a=51.9$ & $a=0.367$ & $\mathrm{~b}=14.9$ & $\mathrm{~b}=1.20$ \\
\hline \multirow{8}{*}{$5 \mathrm{GHz}$} & \multirow{4}{*}{ LOS } & 12 & Rician & -46.2 & 0.416 & 3.94 & 0.294 \\
\hline & & 13 & Rician & -45.8 & 0.365 & 3.45 & 0.258 \\
\hline & & 23 & Rician & -45.9 & 0.411 & 3.89 & 0.291 \\
\hline & & 123 & Rician & -44.8 & 0.380 & 3.59 & 0.268 \\
\hline & \multirow{4}{*}{ NLOS } & 12 & Lognormal & 3.91 & 0.00854 & 0.0856 & 0.00624 \\
\hline & & 13 & Lognormal & 3.91 & 0.00791 & 0.0796 & 0.00564 \\
\hline & & 23 & Lognormal & 3.91 & 0.00744 & 0.0741 & 0.00521 \\
\hline & & 123 & Lognormal & 3.91 & 0.00762 & 0.0761 & 0.00542 \\
\hline
\end{tabular}





Fig. 3. Diversity gains for received power at $90 \%$ signal reliability (a) two-branch channel combining, (b) three-branch channel combining

results at 3, 4 and $5 \mathrm{GHz}$ through the use of spatial diversity techniques for both LOS and NLOS (Fig. 3a). For 2-channel diversity combining the narrowband diversity gains over all of the frequencies were in the range of 1.7 to $3.3 \mathrm{~dB}$ for LOS and 1.8 to $3.4 \mathrm{~dB}$ for NLOS. Gains for the LOS and NLOS arrangements where thus similar. It was also found that the channel combination $1 \& 3$ offered the largest gain most frequently $(67 \%)$. The largest diversity gains were realized by the use of 3-branch diversity techniques (Fig. $3 b)$. However, there was a marginal increase over the 2branch results with an average of only $0.6 \mathrm{~dB}$ of additional diversity gain. Gains for the NLOS arrangements ranged from 2.8 to $4.2 \mathrm{~dB}$ and were slightly higher than those for the LOS which is beneficial as the results indicate lower received power for NLOS scenarios.

\section{Conclusion}

Spatial diversity gains at $90 \%$ signal reliability have been investigated for an off-body multiple antenna transmitter system for frequencies of 3,4 , and $5 \mathrm{GHz}$ in a generic indoor stairwell with a wall-mounted receiver base station. Furthermore, statistical models were developed for the various empirical datasets. It was observed that the 2branch spatial diversity combining techniques offer signal gains over the original single channels for each of the three frequencies. For LOS the minimum gain realized was $1.7 \mathrm{~dB}$ and the largest was $3.3 \mathrm{~dB}$. For NLOS the minimum and maximum diversity gains were 1.8 and $3.4 \mathrm{~dB}$, respectively. Use of 3-branch combining added additional gains; 2.5 to $4.0 \mathrm{~dB}$ for LOS and 2.8 to $4.2 \mathrm{~dB}$ for NLOS. Finally, it was realized that for NLOS measurements the best fit statistical distributions models for the individual channels are found to change when NLOS channels are combined; this illustrated the improvement in lessening deep fades and increasing overall link reliability in the environment, particularly for higher body shadowing scenarios. Considering the deep fades experienced in narrowband, use of such diversity techniques are justifiable for narrowband indoor off-body communications in stairwells, with 3-branch diversity offering marginal additional gain over the 2-branch case.

\section{References}

[1] Cho, Y., Kim, J., Yang, W., Kang, C.L.: 'Antenna diversity and Space-Time coding techniques, MIMO-OFDM wireless communications with MATLAB', (Wiley-IEEE Press, 2010), pp. 281-307.

[2] Michalopoulou, A., Alexandridis, A.A., Zervos, T., et al.: 'Handheld terminal vs. bodyworn antenna systems: A comparative study of MIMO systems performance,' IEEE MTT-S Intl. Microwave Workshop on Wireless Sensing, Local Positioning, and RFID, 24-25 Sept. 2009, pp. 1-4.

[3] Ren, Y-J.: 'Low-profile wearable UHF antenna for portable radios and radar applications,' Gen. Assembly and Sci. Symp., 2011 XXXth URSI, 13-20 Aug. 2011, pp. 1-4.

[4] Farserotu, I., Hutter, A., Platbrood, F., et al.: 'UWB transmission and MIMO antenna systems for nomadic user and mobile PAN', Wireless Personal Communications, 2002, 2, (22), pp. 297-317.

[5] Hanzo, L.L., Alamri, O., El-Hajjar, M., et al.: 'NearCapacity Multi-Functional MIMO Systems: SpherePacking, Iterative Detection and Cooperation', (Wiley IEEE Press, 2009), pp. 469.

[6] Cotton, S.L., Scanlon, W.G.: 'Measurements, Modeling and Simulation of the Off-Body Radio Channel for the Implementation of Bodyworn Antenna Diversity at 868 MHz', IEEE Trans. Ant. Prop., 2009, 57, (12), pp. 39513961 .

[7] Ngo, H.Q., Larsson, E.G., Marzetta, T.L.: 'Energy and Spectral Efficiency of Very Large Multiuser MIMO Systems,' IEEE Trans Comm., 2013, 61, (4), pp. 1436-1449.

[8] Van Torre, P., Vallozzi, L., Hertleer, C., et al.: 'Indoor Off-Body Wireless MIMO Communication With Dual Polarized Textile Antennas,' IEEE Trans. Ant. Prop., 2011, 59, (2), pp. 631-642. 
This article has been accepted for publication in a future issue of this journal, but has not been fully edited.

Content may change prior to final publication in an issue of the journal. To cite the paper please use the doi provided on the Digital Library page.

[9] Lim, S.Y., Yun, Z., Iskander, M.: 'Propagation Measurement and Modeling for Indoor Stairwells at 2.4 and 5.8 GHz”, IEEE Trans. Ant. Prop., 2014, 62, (9), pp. 47544761 .

[10] Lim, S.Y., Yun, Z., Baker, J.M., et al.: 'Propagation Modeling and Measurement for a Multifloor Stairwell', IEEE Ant. Wireless Prop. Letters, 2009, 8, pp. 583-586.

[11] Wang, Y., Wang, X-L., Qin, Y., et al.: 'An empirical path loss model in the indoor stairwell at $2.6 \mathrm{GHz}$ ', IEEE Intl. Wireless Symp. (IWS), 24-26 March 2014, pp. 1-4.

[12] Marinova, M., Thielens, A., Tangh, E., et al.: 'Diversity Performance of Off-body MB-OFDM UWB-MIMO,' IEEE Trans. Ant. Prop. 2015, 63, (7), pp. 3187-3197.

[13] Aziz, O.A., Rahman, T.A.: 'Comparison of indoor propagation models for multi floor staircase at $900 \mathrm{MHz}$ and $1800 \mathrm{MHz}$, IEEE 2nd Intl. Symp. on Telecommunication Technologies (ISTT), 24-26 Nov. 2014, pp. 174-178.

[14] Yu Y., Dong, J., Ye, A., et al.: 'Effect of antenna height on propagation characteristics under indoor stair environment', IEEE 3rd Asia-Pacific Conf. Ant. Prop. (APCAP), 26-29 July 2014, pp. 710-712.

[15] Yu, Y., Liu, Y., Lu, W., et al.: 'Path loss model with antenna height dependency under indoor stair environment', Intl. Journal Ant. Prop., 2014, pp. 1-6.

[16] S. Y. Lim, Z. Yun, J. M. Baker, N. Celik, H. S. Youn, M. F. Iskander, "Propagation Modeling and Measurement for a Multifloor Stairwell," IEEE Ant. W. Prop. Let., 2009, 8, pp.583-586.

[17] S. Y. Lim, Z. Yun, M. F. Iskander, "Radio propagation measurements in multifloor indoor stairwells," 2010 IEEE Intl. Conf. W. Info. Tech. Sys., Honolulu, 2010, pp.1-4.

[18] Y. Wang, X. L. Wang, Y. Qin, Y. Liu, W. j. Lu, H. b. Zhu, "An empirical path loss model in the indoor stairwell at 2.6 GHz," 2014 IEEE Intl. W. Symp., X'ian, 2014, pp.1-4.

[19] S.Y. Lim, Z. Yun, M.F. Iskander, "Propagation Measurement and Modeling for Indoor Stairwells at 2.4 and 5.8 GHz", IEEE Trans. Ant. Prop., Sept 2014, 62, (9), pp.4754-4761.

[20] Catherwood, P.A., Scanlon, W.G.: 'Measurement errors introduced by the use of co-axial cabling in the assessment of wearable antenna performance in off-body channels', Proc. 5th Eu. Conf. Ant. Prop. (EUCAP), 11-15 April 2011, pp. 3787-3791.

[21] Catherwood, P.A., Scanlon, W.G.: 'Body-centric ultrawideband multi-channel characterisation and spatial diversity in the indoor environment', IET Microwaves, Antennas and Propagation, 2013, 7, (1), pp. 61-70.

[22] Fort, A., Ryckaert, J., Desset, C., et al.: 'Ultrawideband channel model for communication around the human body", IEEE J. Selected Areas Comms., 2006, 24 (4) pp. 927-933.

[23] Dietrich, C.B., Dietze, K., Nealy, J.R., et al.: 'Spatial, polarization and pattern diversity for wireless handheld terminals', IEEE Trans. Ant. Prop., 2001, 49, pp.1271-1281.

[24] Saunders, S.R., Aragón-Zavala, A.: 'Overcoming Wideband Fading, Antennas and propagation for wireless communication system', (John Wiley, UK, 2007, 2nd ed.).

[25] Babich F, Lombardi G. "Statistical analysis and characterization of the indoor propagation channel", IEEE Trans. on Comms., 2000, 48, (3), pp.455-464.

[26] Rappaport, T: 'Wireless Communications: Principles and Practice' (Prentice Hall, USA, 2001, 2nd ed.).

[27] Bansal, R (Ed.): 'Handbook of Engineering Electromagnetics', (Taylor and Francis, (Reprint) 2012). 